\title{
СОВРЕМЕННАЯ ЦИФРОВАЯ ЭКОНОМИКА: ОСНОВНЫЕ ХАРАКТЕРИСТИКИ, ИННОВАЦИИ И ЭКОНОМИЧЕСКИЙ РОСТ
}

\author{
(C) 2021 Амурский А. А. \\ директор по развитию ООО «Элемент», Россия, Благовещенск \\ E-mail: amursaa@yandex.ru
}

В данной статье рассматриваются вопросы развития современной цифровой экономики как новой формы распределения ресурсов для формирования качественного экономического роста. Автор выделяет базовые характеристики современной цифровой экономики: платформизацию, обработку данных и инклюзивность. В работе также рассматриваются вопросы технологических инноваций как фундаментальной движущей силы экономического роста: технологические новинки, прикладные инновации, межотраслевая интеграция и скорость инновационных разработок. В статье также анализируется влияние национальных особенностей экономического роста на развитие современной цифровой экономики: крупномасштабность экономики, структурные реформы, уровень внутреннего потребления и национальные инфраструктурные проекты.

Ключевые слова: цифровая экономика; экономический рост; инновация; данные; платформа; интеграция.

\section{Введение}

Будучи залогом высокой производительности, цифровая экономика не только демонстрирует собственное ускорение, но и становится важным двигателем качественного развития экономики развитых и развивающихся стран.

Структура цифровой экономики 2.0 основана на новых облачных и сетевых технологиях, а в экономической организации произошли революционные изменения в бизнес-моделях, организационных моделях и моделях занятости. Сравнивая основные компании, занимающиеся технологиями двух эпох развития цифровой экономики (в 1995 и 2020 годах), мы можем обнаружить, что между ними есть фундаментальные различия с точки зрения технического уровня и направления бизнеса. Современная цифровая экономика - это совершенно новая экономическая форма и метод распределения ресурсов, которая обеспечивает важный импульс для усиления экономических инноваций и способствует формированию качественного экономического роста. В данной работе мы рассмотрим базовые характеристики современной цифровой экономики, виды технологических инноваций и влияние экономического роста национальной экономики на развитие экономики цифровой.

Три базовые характеристики цифровой экономики 2.0

Цифровая экономика 2.0, основанная на новой инфраструктуре цифровых технологий, имеет три основных характеристики: платформизацию, обработку данных и инклюзивность.

1) Цифровая платформа - это основа Цифровой экономики 2.0. При использовании платформ (поисковые системы, шеринговые платформы, социальные сети и др.) информационный поток не блокируется гигантами системы производственных цепочек поставок [1]. Значительно сокращаются расстояние между поставщиками и потребителями и затраты на связь, что стимулирует формирование крупномасштабного сотрудничества. Малые и средние предприятия различных типов и отраслей получают возможность напрямую обслуживать потребителей через доступ к платформе. В настоящее время на таких платформах, как Taobao и Tmall рынок не только собрал десятки миллионов продавцов. Внутреннее управление предприятием, аутсорсинг персонала, другие сопутствующие услуги и инструменты исчисляются сотнями тысяч [2].

2) Обработка данных. Наиболее важной особенностью Цифровой экономики 2.0 является высокая степень обработки данных. Компании в индустриальную эпоху реализовали оцифровку с использованием ИТ-технологий. В эпоху цифровой экономики 2.0 потоки данных и их совместное использование управляют бизнеспроцессами, выходящими за рамки корпоративных границ, и создают новые сетевые ценности [3].

3) Инклюзивность. В среде современной 
цифровой экономики реализованы инклюзивные технологии, инклюзивные финансы и инклюзивная торговля. Бизнес-форма предоставления услуг по запросу, представленная облачными вычислениями, позволяет отдельным лицам и различным предприятиям легко получать необходимые хранилища и сетевые ресурсы по очень низкой цене вместо того, чтобы покупать дорогое оборудование и программные продукты. Согласно расчетам Alibaba Research Institute, использование облачных вычислений может снизить затраты предприятий, использующих ИТ на 70\% и повысить эффективность инноваций в 3 раза [4]. В финансовой сфере новый тип модели кредитного скоринга, основанный на кредитовании через Интернет, играет незаменимую роль в реализации инклюзивного финансирования. В области глобальной торговли цифровая экономика 2.0 открыла миру новую реальность инклюзивной торговли, при которой все виды торговых субъектов могут участвовать в мировой торговле и получать от нее прибыль, а порядок торговли будет более справедливым [5].

\section{Технологические инновации}

Технологические инновации - это фундаментальная движущая сила экономического роста и основа экономических инноваций. В настоящее время мировая экономика претерпевает серьезные корректировки и изменения, и страны уделяют все больше внимания инновациям и развитию. Инновационный драйв заменил факторный драйв как главный двигатель экономического развития, а усиление экономических инноваций стало неизбежным выбором развитых и развивающихся экономик [6].

1) Оригинальные технологические новинки. Цифровые технологические новинки - это основа технологической конкуренции в современном мире. Они все чаще становятся фактором принятия управленческих решений, а также являются ключевым фактором международной конкурентоспособности экономического субъекта. По сравнению с традиционными промышленными технологиями цифровые технологические новинки демонстрируют систематические различия в непрерывности и последовательности развития.

2) Прикладные инновации. В настоящее время наиболее широко используемыми прикладными технологиями являются модели с открытым исходным кодом. В 2019 году сделка по приобретению IT-компания F5 Networks poc- сийского проекта Nginx с открытым исходным кодом за \$670 млн. ярко иллюстрирует новый тренд: сервисы с открытым исходным кодом давно перестали быть альтруистичными способом создания новых продуктов, а превратились в новую практичную бизнес-модель, заточенную на получение прибыли [7]. В настоящее время такие технологии широко используются в медицине, образовании, государственных делах, потреблении и других сферах, обеспечивая на практике образование огромных дивидендов.

3) Межотраслевая интеграция на основе цифровых технологий расширяет рыночное пространство для совместного создания и совместного использования разработок. Межотраслевая координация также благотворно влияет на процессы противодействия рискам [8]. Совместное развитие ряда отраслей народного хозяйства, переплетение и интеграция их опыта и технологий само по себе формирует инновационный фон, когда несколько отраслей взаимовдохновляют и взаимосовершенствуют друг друга.

4) Интенсивность инноваций. Быстрый подъем цифровой экономики не только олицетворяет технологические изменения в мировом хозяйстве, но и демонстрирует активное внедрение инноваций в концепции развития, в операционное управление и в бизнес-модели. В настоящее время технологии 5G, искусственный интеллект, видео сверхвысокой четкости, виртуальная реальность, блокчейн и другие развивающиеся инновации в области цифровых технологий продолжают набирать обороты и широко используются в различных областях и связях, формируя наложенный эффект технологических и промышленных инноваций, ведущий к появлению новых моделей и новых форм бизнеса, демонстрирующий тенденцию инновационноинтенсивного развития с множеством прорывов и ярких событий.

Влияние экономического роста на развитие современной цифровой экономики

Не только цифровые технологии оказывают влияние на современную экономику, но и национальные особенности экономик разных стран оказывает существенное влияние на развитие процессов цифровизации.

(1) Крупномасштабная национальная экономика обеспечивает высококачественную почву для роста цзифровой экономики. По данным Национального бюро статистики КНР, Валовой внутренний продукт (ВВП) в 2020 году впервые 
превысил 100 трлн. юаней [9]. Китайская экономика в настоящее время является законченной промышленной системой с огромным внутренним рынком спроса, с обширным пространством для маневра в политике, значительными институциональными преимуществами. Сверхбольшая экономика Китая чрезвычайно открыта, инклюзивна и охотно принимает инновации, что полностью отвечает потребностям различных сценариев новых технологий. В то же время цифровая экономика также является важным путем преобразования преимуществ сверхбольших экономик в конкурентные преимущества.

(2) Структурные реформы в сфере предложения способствуют интеграции цифровой и реальной экономики. В настоящее время углубление структурной реформы предложения является основной линией и отправной точкой для качественного развития современной экономики. Содействие структурным реформам со стороны предложения способствует дальнейшему стимулированию жизнеспособности и творчества микроэкономических субъектов, порождая новые рыночные возможности со стороны производства, способствуя быстрому и упорядоченному поступлению факторов производства в развивающиеся отрасли и подталкивая обрабатывающую промышленность к внедрению цифровых технологий. Развитие цифровой экономики тесно связано с осуществлением структурных реформ в сфере предложения. При активной поддержке таких реформ цифровая экономика и реальная экономика движутся к органической и эффективной интеграции, а факторы производства цифровой экономики продвигаются во всех сферах реальной экономики [10].

(3) Повышение уровня потребления дает новый импульс для роста цифровой экономики. В последние годы роль внутреннего спроса в цифровой экономике ряда стран усилилась, особенно с наступлением пандемии Covid-19. На фоне ускоряющихся изменений в потребительской среде, непрерывного появления новых бизнесмоделей и постоянного совершенствования потребительских концепций, потребительский сектор современных национальных экономик претерпевает всеобъемлющие, структурные и системные глубокие изменения, а структура потребления переходит от физического потребления к сервису [11]. Потребление ускорило трансформацию, масштабы потребления ин- формации увеличивались, а интеграция онлайни офлайн-потребления стала очевидной, придавая новый импульс развитию и росту цифровой экономики.

(4) Новая инфраструктура создает новые возможности для развития цифровой экономики. В настоящее время самые крупные экономики мира стали уделять особое внимание развитию инфраструктурных стратегий для антициклической перестройки национального хозяйствования. В частности, Китай в ближайшие несколько лет сосредоточится на укреплении строительства новой экономической и социальной инфраструктуры с применением технологий 5G, искусственного интеллекта и созданием центров обработки данных. По сравнению с традиционной новая инфраструктура учитывает как стимулирование краткосрочного платежеспособного спроса, так и развитие долгосрочных потребностей в модернизации. Она реализует интеграцию и оптимизацию инфраструктуры, связанной с цифровой экономикой, не только на функциональном уровне, но и на базовом уровне [12].

\section{Выводы}

В эпоху глобальной пандемии цифровая экономика убедительно демонстрирует технологические преимущества не только по сравнению с традиционными формами хозяйствования, но и по сравнению с предыдущей эпохой собственного развития. Эти преимущества стали возможны в связи с появлением интернет-платформ для оптимизации информационных потоков, возрастанием скорости обработки данных и развитием технологий, финансов и торговли на основе «инклюзивности». Технологические инновации стали главной движущей силой глобального и национального экономического роста. Обладание технологическими новинками и прикладными технологиями все чаще становятся основной для принятия управленческих решений и развития международной конкурентоспособности экономического субъекта. На ряду с этим национальные особенности экономического роста, в свою очередь, также оказывают заметное влияние на развитие цифровых технологий. Развитие инфраструктуры, реформирование структуры внутреннего предложения и потребления, масштабирование национального хозяйства, - все это обеспечивает высококачественную почву для роста цифровой экономики. 


\section{Библиографический список}

1. Гелисханов И.З., Юдина Т. Н., Бабкин А. В. Цифровые платформы в экономике: сущность, модели, тенденции развития. Научно-технические ведомости СПбГПУ // Экономические науки. - 2018. - № 6. - С.22-36.

2. Bukht R., Heeks R. Defining, Conceptualising and Measuring the Digital Economy / International Organisations Research Journal. 2018. Vol. 13(2). pp. 143-172.

3. Sheremetyeva E.N. Digital Economy: Terminology And Efficiency. Conference: Proceedings of the II International Scientific Conference GCPMED 2019 - «Global Challenges and Prospects of the Modern Economic Development». March 2020.

4. Alibaba Innovative Research. URL: https://damo.alibaba.com/air/?lang=en (дата обращения 20.07.2021).

5. Wong J. Digital Economy and Inclusive Trade. ESCAP. URL: https://www.unescap.org/sites/default/files/Digital_ Economy_Inclusive_Trade.pdf (дата обращения 20.07.2021).

6. Brass I., Hornsby D. Digital Technological Innovation and the International Political Economy. The Palgrave Handbook of Contemporary International Political Economy Publisher: Palgrave Macmillan, 2019.

7. Как заработать миллионы на открытом коде: от Red Hat до Nginx. URL: https://www.forbes.ru/ tehnologii/373927-kak-zarabotat-milliony-na-otkrytom-kode-ot-red-hat-do-nginx (дата обращения 20.07.2021).

8. Burlay E., Simchenko N., Tsohla S. Principles of cross-sectoral network interaction between structures in the digital economy. Conference: Proceedings of the Volgograd State University International Scientific Conference «Competitive, Sustainable and Safe Development of the Regional Economy», 2019.

9. Экономика Китая вышла на новый уровень. China daily. URL: https://baijiahao.baidu.com/s?id=169289631720 2819321\&wfr=spider\&for=pc (дата обращения 20.07.2021).

10. Liu S., Zhao D. Supply-side structural reform of supply-side theory and control strategy of economy / Quarterly Journal of Indian Pulp and Paper Technical Association. 2018. Vol. 30. No3. pp. 1-8

11. Ignatov A. The Digital Economy of BRICS: Prospects for Multilateral Cooperation / International Organisations Research Journal. 2020. Vol. 15. No 1.pp. 31-62.

12. Garnov A. P., Garnova V.YU., Shabaltina L. V., Begishev I. R., Panferova L. V. New opportunities for the digital economy: the implementation of an effective state innovation policy / Journal of environmental treatment techniques. 2020. Vol. 4. pp. 1321-1325. 